\title{
LENGUAJE, FANTASÍA Y LITERATURA EN INVITACIÓN A la melancolía de Andrés Martínez Oria
}

\author{
LANGUAGE, FANTASY AND LITERATURE IN ANDRÉS MARTÍNEZ ORIA'S \\ INVITACIÓN A LA MELANCOLÍA \\ SAMUel RodríGuez RodRÍGUEZ* \\ Universidad Complutense de Madrid, España. samrod02@ucm.es
}

Recibido el 3 dE ABRIL DE 2020 APROBAdo El 22 DE MAYo de 2020

\begin{abstract}
RESUMEN
Andrés Martínez Oria (Salamanca, 1950) ha mostrado gran interés por la utilización de la novela como exploración metafísica, en ocasiones con aspiraciones enciclopédicas. Invitación a la melancolía (2014) representa un magnífico ejemplo de novela filosófica, en donde la breve trama es el punto de partida de un largo viaje en torno a la melancolía.
\end{abstract}

En este artículo nos centraremos en varios aspectos abordados en el texto. Primeramente, la relación entre lenguaje y melancolía; en segundo lugar, la fantasía (melancólica) y su expresión estetizada a través de la literatura $y$, finalmente, las hipotéticas posibilidades de la literatura como sistema de (auto)conocimiento de una realidad oculta, pero palpada tras la mirada lúcida del melancólico. La principal herramienta de análisis será la filosofía, además de la psiquiatría, el psicoanálisis y los estudios literarios.

\section{Palabras clave}

Lenguaje, fantasía, literatura, Invitación a la melancolía, Martínez Oria.

\section{Abstract}

Andrés Martínez Oria (Salamanca, 1950) has shown great interest in the use of the novel as a metaphysical exploration, sometimes with encyclopedic aspirations. Invitación a la melancolía (2014) represents a magnificent example of philosophical novel where the short plot is the starting point of a long journey around melancholy.

In this paper, we will focus on several aspects addressed in the text. In the first place, the relationship between language and melancholy; in the second place, fantasy (melancholic) and its aesthetised expression through literature and, finally, hypothetical possibilities of literature as a system of (self)knowledge of a hidden reality but palpable behind the lucid glance of the melancholic individual. The main tool of analysis will be philosophy in addition to psychiatry, psychoanalysis and literary studies.

\section{KeY WORDS}

Language, fantasy, literature, Invitación a la melancolía, Martínez Oria.

** (D) orcid.org/0000-0001-6892-1234 Google Scholar 
Andrés Martínez Oria (Salamanca, 1950), pese a ser poco conocido en las letras hispanas, se ha revelado como autor prolífico en los últimos años. Este profesor jubilado de lengua y literatura publicó su primera novela, Más allá del olvido (2007), con 57 años. A partir de entonces su producción literaria ha sido intensa, centrándose en la novela (El raro extravío del viajante Eterio en el pinar de Xaudella, 2008; El silencio de la púrpura, 2008; Jardín perdido, 2009; Invitación a la melancolía, 2014; y Chafariz de Lisboa, 2018), el libro de viajes (Flores de malva, 2011; y Flores de hinojo, 2019) y el cuento ("Sólo quiero morir, señor cónsul", 2001, "El bar de la curva", Premio Internacional de Cuentos “Miguel de Unamuno" en el año 2000, y "La misa pontifical”, 2010). Asimismo, colabora frecuentemente como cronista en diarios provinciales, fundamentalmente de Astorga (León), donde reside.

La factura literaria de sus textos no siempre resulta impecable. Sin embargo, Martínez Oria ha mostrado un interés poco común por la utilización de la novela como exploración metafísica, en ocasiones con aspiraciones enciclopédicas (Suárez Martínez 2014). Precisamente, Invitación a la melancolía representa un ejemplo como pocos de novela filosófica, en donde la breve trama es el punto de partida de un largo viaje en torno a la melancolía: entre los archivos de Correos de una pequeña localidad castellanoleonesa encuentran una carta extraviada de 1948 cuyo remitente, en Buenos Aires, es Umbelina Lasar, y el destinatario, en un pueblo leonés, su marido Eligio Monteamaro, quien esperó durante años junto a su hijo la vuelta de su esposa, en búsqueda de un hijo perdido allí, nacido de un anterior matrimonio del que quedó viuda. Así, Andrés -narrador-protagonista en el tiempo cero de la narración- pretenderá resolver el misterio de una carta a la que no puede tener acceso, y para ello acudirá al único testigo vivo de aquella historia, Ariel Velasco, quien a su vez le sumergirá en mise en abyme en múltiples historias, propias y ajenas. Finalmente descubre el contenido de la carta: Umbelina escribió a su marido e hijo que iba a morir tras buscar de manera infructuosa a su hijo mayor. La melancolía se apoderó de ella y, en una nota adjunta del hotel en donde se aloja, se descubre que se suicidó.

Esta trama se desarrolla en pinceladas sueltas a lo largo de la novela, repleta de anacronías históricas y ficcionales, porque la verdadera protagonista es la exploración metafísica sobre uno mismo y su entorno de cada uno de sus personajes, partiendo de la autoficción del narrador- 
protagonista, con quien el propio Andrés Martínez Oria jugará como alter ego autoficcional sumergido en la melancolía, omnipresente en esta “hipernovela" de 542 páginas (Suárez Martínez 2013). Sin embargo, no son estas cuestiones literarias las que pretendemos analizar aquí, sino el sustrato filosófico de Invitación a la melancolía. Para ello nos centraremos en varios aspectos abordados en el texto: la relación entre lenguaje y melancolía, la fantasía (melancólica) y su expresión estetizada a través de la literatura y, finalmente, las hipotéticas posibilidades de la literatura como sistema de (auto)conocimiento de una realidad oculta pero palpada tras la mirada lúcida del melancólico. La principal herramienta de análisis será la filosofía, además de la psiquiatría, el psicoanálisis y los estudios literarios.

\section{Lenguaje y melancolía}

La relación compleja entre lenguaje y melancolía asoma en cuanto intentamos definir esta última. Así se atisba en el texto de Martínez Oria. Durero, en su famoso grabado de 1514, Melancolía I, "concibió la Melancolía como esa doncella pensativa en que se transfigura el genio creador" (127), considerando así la melancolía como un profundo estímulo creativo para un sujeto que se niega a asumir la vida tal cual se la imponen, y para ello (re)construye su mundo. Sin embargo, "la melancolía conduce finalmente a la inactividad y el ensimismamiento, pero de dónde viene, cuál es la fuente de esa tristeza desconocida, ¿es un estado depresivo pasajero, una manifestación del carácter permanente o la actitud de abandono que sigue al desconcierto espiritual tras la búsqueda?" (127). Martínez Oria, comprensiblemente, no logra dar respuesta a estas cuestiones. De hecho, tal y como señala Földényi, "la historia de la melancolía es también la historia interminable del intento de precisar el concepto" (12). Y es que los conceptos, las palabras, la gramática y el lenguaje pretenden ordenar -ilusoria y artificialmenteuna realidad compleja, la vida -el caos- en eterno fluir, dándose así "la paradoja más propia de la lengua y de la comunicación: las palabras revelan poco porque contienen demasiado" (9). Es decir, su significado (connotativo) depende de la subjetividad de cada sujeto, implicando así múltiples ideas en un concepto y lenguaje imperfectos por imprecisos. "La palabra, para alcanzar verdadero significado y significancia, ha de ser consciente de su servidumbre y comunicar también fragilidad" (910). Y es la fragilidad, la contingencia, la base de la vida. Según señala Martínez Oria: 
de esa conciencia del fluir nace la certeza de la brevedad, fuente de la melancolía, tan difícil de curar. La melancolía brota de un aquí que aspira a infinito, de un ahora que quiere ser eterno, de un yo que se escinde en otros y quiere ser todos. [...] Conciencia de la finitud, la falta de solidez de todo, la ausencia de sentido firme y definitivo de la existencia. Todo ser vivo está destinado a desaparecer, y la materia inerte se transforma en algo distinto. Nada permanecerá igual para siempre (118).

Pero aceptar nuestra propia contingencia dentro de una sociedad educada en el rechazo a la finitud puede suponer un desgarro en ocasiones inasumible: "solo de pensarlo, pensar en la idea de la levedad, en la idea de la fugacidad, en la idea de inconsistencia, en el puro azar de la vida, nace el vértigo y se me nubla la cabeza. Me da vueltas todo, me mareo" (226). Ese "sombrío vértigo" (13) se identificaría con el "vértigo de la libertad" de Kierkegaard, que "surge cuando, al querer el espíritu poner la síntesis, la libertad fija la vista en el abismo de su propia posibilidad" (61). La síntesis se refiere a la intersección buscada por el ser humano entre lo finito y lo infinito. He aquí el abismo del cual resulta imposible apartar la mirada, ya que en él podemos (re) conocernos. En palabras de Martínez Oria, "una vez que se ha abierto la ventana, estamos obligados a mirar, aunque lo observado sea un horror, quizá por eso" (25-26). Y, dentro del abismo, ¿qué papel juega el lenguaje?

El protagonista de Invitación a la melancolía sostiene que las palabras llevan a la nada:

¿cómo soy tan osado, continúo, de atreverme a quebrantar el silencio con el ruido, sabiendo que toda escritura estriba en la nada y apunta a la nada, por mucho que pretenda echar raíces en lo firme y aspire a hablar de lo absoluto? (25)

Pero, ¿es la nada un elemento negativo? El melancólico atisba en la nada un punto de encuentro con el infinito, pues,

erige la Nada en fundamento del mundo. Pero la Nada, siendo nada, resulta inasible: mora en el corazón y es inseparable de la concepción melancólica de la vida: presupone el Algo, sin el cual la Nada sería inimaginable; pero la sombra de la Nada también se proyecta en el Algo, que de esta manera se oculta ante el melancólico bajo el velo 
de lo desconocido. Deseoso de huir de la Nada, se abalanza como un poseso al mundo palpable y terrenal; pero ese Algo del que querría aferrarse es lo desconocido, y lo desconocido no ofrece un hogar donde refugiarse; adonde quiera que se dirija, pues, siempre será devuelto a su punto de partida: la Nada (Földényi 101-102)

"Por eso, aquello que desde fuera parece carencia [...] por dentro es plenitud [...]. Hasta en la máxima lucidez hay cierto desconsuelo, hasta en el pensamiento más preciso hay oscuridad" (Földényi 10-11). Martínez Oria rechaza un lenguaje y un pensamiento inamovibles, definitivos, porque están en contra de la propia naturaleza del ser humano y nuestro entorno, que ya los estoicos asumieron en constante movimiento. Así, "la lengua, el habla, pretende objetivar la melancolía [...]; por otro lado, al nombrar las cosas por su nombre, obliga al melancólico a colocarse dentro del marco del mundo existente" (Földényi 183), un mundo empero artificialmente ordenado, por el cual se desliza el delicioso caos, el desgarro ante el (re)conocimiento del sinsentido de nuestra propia existencia. Mas el melancólico huye precisamente de ese mundo y de sí mismo. Así, el caso extremo de la melancolía -la depresión- produce la autodestrucción del sujeto, como le sucederá a Umbelina en Invitación a la melancolía:

\begin{abstract}
¿Habrá algún mecanismo de supervivencia cuando nos quedamos indefensos? Todo empezará por un lento abandono, como pereza que se va apoderando de nosotros, una disociación de los conceptos, falta de precisión, pérdida de aquello que buscamos, desconexión que nos irá llevando al apartamiento y la soledad, a la lejanía de las cosas y los seres, y entonces iremos dejando también de ser nosotros, de reconocernos, hasta que se diluya poco a poco nuestro yo y ya no seamos nosotros, tampoco otros, no seamos nadie (269).
\end{abstract}

La depresión sería un mecanismo de autodefensa ante una realidad que nos resulta insoportable, del mismo modo que perdemos el conocimiento ante dolores físicos extremos. Seligman en Helplessness desarrolla a este respecto la "teoría de la incapacitación aprendida", según la cual "los organismos, al ser expuestos a acontecimientos incontrolables, aprenden que es inútil responder. [...] si el organismo aprende que el trauma es incontrolable, el miedo da paso a la depresión" (cit. en Jackson 225). Engel y Reichsman hablan de la "reacción de depresión-retraimiento", 
consistente en la necesidad de reducir la actividad del metabolismo frente al agotamiento o una amenaza, que partiría de nuestra más tierna infancia. Así, cuando una respuesta anterior de angustia y llanto no tuvo como consecuencia la llegada de la madre y produjo ansiedad grave y finalmente agotamiento, el niño aprende que "la reacción de depresiónretraimiento era la más económica y la que menor energía consumía" (cit. en Jackson 223). Ahora bien, ¿cómo se manifiesta esto en el lenguaje?

Tal y como señala Kristeva, "le ralentissement moteur, affectif et idéïque caractéristique de l'ensemble mélancolico-dépressif" (46), afectando también a sus capacidades comunicativas. Así,

notre don de parler, de nous situer dans le temps pour un autre, ne saurait exister ailleurs qu'au-delà d'un abîme [...]. La mélancolie s'achève alors dans l'asymbolie ${ }^{1}$, la perte de sens: si je ne suis plus capable de traduire ou de métaphoriser, je me tais et je meurs (54).

Pero el depresivo se hunde en el "vértigo de la libertad" kierkegaardiano, de modo tal que "les objets et les signifiants [...] prennent la valeur du non-sens: le langage et la vie n'ont pas de sens" (Kristeva 63). Para el melancólico (en este caso depresivo), "hasta la palabra, objetivación del espíritu, se desintegra: pierde su carácter definitorio; y si para los otros la lengua representa una posibilidad, para el melancólico constituye un obstáculo (Földényi 51). Esto es así pues el melancólico ha descubierto su propio sinsentido, la gratuidad de la existencia que provoca la náusea en Roquentin (Sartre 187) al considerar inasumible esta revelación. De esta manera, "para quien entrevé los secretos más recónditos de la existencia, las palabras pierden su significado, se agrietan y sólo revelan su carácter efímero. El melancólico se ve obligado al silencio" (Földényi 51). Por ello, se sumerge "en el mutismo eterno", y reconoce "el carácter transitorio de toda generación y la insuficiencia de la totalidad" (Földényi 53). En definitiva, "le discours déprimé, bâti de signes absurdes, de séquences ralenties, disloquées, arrêtées, traduit l'effondrement du sens dans l'innommable où il s'abîme" (Kristeva 63).

Sin embargo, más allá de esta forma extrema de la melancolía -la depresión-Martínez Oria se centra sobre todo en sus formas intermedias, relacionadas con la mirada crítica y pesimista de la realidad circundante,

\footnotetext{
${ }^{1}$ Se trata de una enfermedad neurológica consistente en la pérdida del componente afectivo, normalmente desagradable, ante el dolor.
} 
también como categoría estética y creadora, en donde entran en juego la fantasía y la imaginación.

\title{
II. Fantasía (melancólica) y literatura
}

Martínez Oria nos informa en esta novela enciclopédica de que en la Edad Media y el Renacimiento se consideraba el "síndrome melancólico" como spiritus phantasticus, es decir, un "desorden de la fantasía o vitium corruptae immaginationis" (128). La fantasía sería, por tanto, negativa, al tiempo que la razón asume el carácter positivo. Así se aprecia también en pleno siglo XVIII, en la novela Rasselas de Samuel Johnson:

\begin{abstract}
Disorders of intellect happen much more often than superficial observers will easily believe. Perphaps, if we speak with rigorous exactness, no human mind is in its right state. There is no man whose imagination does not sometimes predominate over his reason, who can regulate his attention wholly by his will [...]. All power of fancy over reason is a degree of insanity. [...] the mind, in weariness or leisure, recurs constantly to the favourite conception, and feasts on the luscious falsehood whenever she is offended with the bitterness of truth. By degrees the reign of fancy is confirmed; she grows first imperious, and in time despotik. Then fictions begin to operate as realities, false opinions fasten upon the mind, and life passes in dreams of rapture of anguish (100).
\end{abstract}

La "mente, fatigada u ociosa", puede ser causa de males infligidos contra nosotros o los demás (Rodríguez 2019). Svendsen distingue dos tipos de tedio: el situacional, que tendría lugar puntualmente ante hechos concretos, y el existencial, según el cual el sujeto experimenta la carencia de sentido del mundo (33). Esta concepción negativa de la fantasía se refleja en múltiples autores. Tal y como recoge Martínez Oria, "psicoanalistas, filósofos y pensadores religiosos [...] condenan sin paliativos la fantasía, manifestación palmaria de lo patológico, producto de facultades inferiores que solo reclaman sensibilidad, nunca razonamiento e inteligencia, fronteriza de los dominios siempre nebulosos del mal" (197). La fantasía es para los psicoanalistas "un puro sueño diurno" (198). Por ello, el autor concluye que "se nos permite en definitiva imaginar, pero con moderación; en ningún caso estará bien visto el vicio de fantasear cuando se es adulto" (200). 
Freud consideró en El poeta y los sueños diurnos que "la actividad creadora reside en las fantasías o sueños diurnos, que vienen a sustituir en el adulto el juego infantil" (198), según nos explica el propio Andrés. Freud subraya la relación entre el juego infantil respecto a la fantasía y la creación artística del adulto:

El niño diferencia muy bien de la realidad su mundo del
juego, a pesar de toda su investidura afectiva; y tiende a
apuntalar sus objetos y situaciones imaginados en cosas
palpables y visibles del mundo real. Sólo ese apuntalamiento
es el que diferencia aún su "jugar" del "fantasear".
Ahora bien, el poeta hace lo mismo que el niño que juega:
crea un mundo de fantasía al que toma muy en serio, vale
decir, lo dota de grandes montos de afecto, al tiempo que
lo separa tajantemente de la realidad efectiva. Y el lenguaje
ha recogido este parentesco entre juego infantil y creación
poética llamando"juegos" \{"Spiel”\} a las escenificaciones del
poeta que necesitan apuntalarse en objetos palpables y son
susceptibles de figuración, a saber: "Luslspiel" \{"comedia";
literalmente, "juego de placer"\}, “Trauerspiel” $\{$ «tragedia»;
«juego de duelo»\}, y designando "Schauspieler" \{“actor
dramático"; "el que juega al espectáculo"\} (128).

De hecho, "todo niño que juega se comporta como un poeta, ya que crea un mundo propio, o, más exactamente, transpone las cosas del mundo donde vive a un nuevo orden de su conveniencia [...]. Lo contrario del juego no es lo serio, sino la realidad" (Freud 127). Profundizaremos en el siguiente apartado en su teoría acerca de la creación -literaria-, en donde se apreciarán las consecuencias estéticas de las aseveraciones aquí expuestas.

La fantasía, por tanto, nos acompaña durante toda la vida, en mayor o menor medida. Cierto es que, como dijo Samuel Jackson, "ninguna mente humana está en su debido estado". Todos vivimos en cierto grado de "locura" que, como la estulticia, resulta cosustancial al ser humano, según nos enseñó Erasmo de Rotterdam: "Si me excluyerais, nadie podría soportar a otro, de tal modo que cada cual se apestaría a sí mismo, de sí mismo sentiría asco y a sí mismo se odiaría" (128). Pues “ ¿hay algo más loco que gustarse a sí mismo, admirarse a sí mismo?" (129). Y es que "¿de qué serviría la belleza, supremo don de los dioses inmortales, si se contaminara con la mancha de la melancolía?" (129). 
De la lectura de estas citas inferimos por un lado la connotación negativa de la fantasía asociada a cierto grado de melancolía frente a la locura "melancólica" de la que habla Rotterdam, de carácter lúcido, al desnudar sin escrúpulos el teatro de la vida -expresada con aguda ironía por el humanista-. Así, "dado que la vida es una comedia en que cada actor lleva su máscara propia, al que arranca las máscaras se le echa de ella; hay que adaptarse a las condiciones existentes, y por ello actúa mal quien no hace así queriendo que el juego deje de serlo" (Rotterdam 61-62). El melancólico sería el actor que, sobre el escenario, en mitad de la obra, osa declarar ante los demás pero, sobre todo, ante sí mismo, el absurdo de la obra representada, granjeándose así las críticas y la marginación de unos compañeros de reparto, dispuestos a mantener la ficción por resultarles más cómodo vivir en la mentira que explorar y asumir una verdad desgarradora. Así lo vio también Freud, al considerar respecto al melancólico que "capta la verdad con más claridad que otros, no melancólicos" (244). Esto es así pues,
cuando en una autocrítica extremada se pinta como insignificantucho, egoísta, insincero, un hombre dependiente que sólo se afanó en ocultar las debilidades de su condición, quizás en nuestro fuero interno nos parezca que se acerca bastante al conocimiento de sí mismo y sólo nos intrigue la razón por la cual uno tendría que enfermarse para alcanzar una verdad así (244).

En definitiva, "en el melancólico podría casi destacarse [...] una acuciante franqueza que se complace en el desnudamiento de sí mismo" (245).

Pero entonces, ¿quién es el loco?, ¿quién es el que vive en una “deliciosa falsedad" autocomplaciente en donde "las ficciones empiezan a operar como realidades"? Martínez Oria nos da la clave: "hay una fantasía inconsciente, la de los sueños, que produce fantasmas incontrolables, y otra consciente, el ensueño diurno, que puede enriquecer la personalidad, darle otra dimensión; es de aquí de donde procede la creación artística" (198). El melancólico -no necesariamente artistausa la fantasía para perderse y (re)encontrarse a sí mismo a través de la experiencia catártica de ser otro. Invitación a la melancolía así lo dice: "no es posible conocernos sin conocer antes al otro, la imagen del otro en el espejo donde debo descubrirme" (31). Se trata de "crear para conocer, proyectarse y sobrevivir" (38), aunque tal vez ilusoriamente, según veremos en el último apartado. El escritor -el Andrés real y el 
autoficticio- se proyecta en sus personajes para conocerse a sí mismo: “Eligio Monteamaro, ser real convertido en personaje imaginado a su medida [la de Velasco], transposición de sí y a la vez ente ficticio con vida y pensamiento (129).

Tal y como asevera Jackie Pigeaud a propósito de El hombre de genio y la melancolía. Problema XXX atribuido a Aristóteles, "la creatividad consiste, en esencia, en una pulsión a ser diferente, en una irreprimible incitación a convertirse en otra persona, a convertirse en todos los demás" (47). Así pues, "no es posible ser uno mismo en profundidad y creador a la vez, más que siendo otro, dejándose convertir en otro; de esta manera uno pude imitar mejor a todos los personajes y a todos los seres" (49). La fragilidad asumida por el melancólico le permite abrirse a otras formas de vida, ampliar su espectro de posibilidades y sacar provecho del sinsentido al (re)conocerse en él y explorar algunas de sus formas. Para Földényi, el melancólico "actúa por su propia voluntad, porque él establece sus propias leyes. Sabe y se da cuenta de que el mundo es un sistema de expectativas; sin embargo, en esta situación ambigua, se muestra incapaz de responder a ninguna de ellas. Debería resignarse a ser una personalidad anormal y enfermiza, puesto que normal es, dicen, quien se conforma con que el mundo sea como es" (114). Él no. Su fantasía melancólica "actúa como arma, porque le permite crear un mundo interno en oposición al externo. El melancólico se entrega a la tristeza con placer masoquista: el alma siempre posee un ámbito al que nadie tiene acceso. Este ámbito se extiende hacia "dentro": a mayor presión externa, más se avanzan las fronteras hacia el interior" (Földényi 189).

No obstante, la divergencia en cuanto a las posibilidades (literarias) de la fantasía podría verse esclarecida mediante la teoría de Marsilio Ficino en torno al alma, expuesta en De vita triplici y analizada exhaustivamente por Klibansky, Panokfsy y Saxl. Para Ficino, "el alma poseía tres facultades distintas que formaban un todo jerárquicamente ordenado: la «imaginatio» o imaginación, la «ratio» o razón discursiva y la «mens» o razón intuitiva" (259). La superior sería la mens, que a nuestro juicio combina razón discursiva circunscrita al puro análisis racional de la realidad inmediata y la "imaginatio", por su capacidad para "intuir" o imaginar a partir de la realidad inmediata y, así, trascenderla. Y ese es el oficio del poeta, del melancólico, del visionario, capaz de aunar razón e imaginación atisbando con su intuición melancólica -inconformista, anhelante, siempre insatisfecha- algo que se le escapa, la nostalgie 
d'unité de Camus, un "appétit d'absolu" (34), de eternidad, de unión del individuo contingente con el universo. Cobra así sentido el "ser el hombre un individuo y, como tal, a la vez él mismo y la especie entera, de tal suerte que la especie entera participa en el individuo y el individuo en la especie entera" (Kierkegaard 30). De ahí que, como explicamos, "no es posible conocernos sin conocer antes al otro, la imagen del otro en el espejo donde debo descubrirme".

Como ya dijera Erasmo de Rotterdam, "la razón es siempre una fuerza reguladora, no es nunca en sí una fuerza creadora; la verdadera creación reclama siempre la presencia de una ilusión" (67). Una ilusión que parte sin embargo de la aceptación del fracaso, de la fragilidad e inconsistencia de las palabras, según explicamos en el anterior apartado. Tal vez por ello "il n'est d'imagination qui ne soit, ouvertement ou secrètement, mélancolique" (Kristeva 15). También Martínez Oria nos recuerda que "La loca de la casa", llamaba santa Teresa en Las moradas a la imaginación, porque nos saca del quicio de la realidad y se salta a la torera todas las convenciones" (196). Esas "convenciones" -impostaciones teatrales- nos impiden explorar el mundo que nos rodea y salir fortalecidos de ello. Sin embargo, es la imaginación, la imagen formada por la fantasía, la que nos transporta a otros mundos, otras vidas, otras formas de pensamiento bajo las que se ampara el melancólico. Y una de esas formas en las que se proyecta y se materializa la fantasía es la literatura, cuya implicación con la melancolía aquí hemos esbozado. Sin embargo, ¿cuál es el resultado de la proyección de la fantasía (melancólica) en la literatura?, ¿es la literatura un bálsamo sincero al melancólico o más bien otro subterfugio teatral para ocultar la realidad? Analizaremos estas cuestiones a continuación.

\section{III. ¿La literatura como redención melancólica?}

El resultado de la proyección de la fantasía (melancólica) en la literatura parece ser el fracaso, ya que "es tanta la distancia de lo real a lo contado, y aun de lo acontecido a la propia percepción de los hechos" (Martínez Oria 54). El lenguaje (literario), según explicamos, resulta insuficiente para expresar la esencia de nuestro pensamiento. Para María Lozano "tampoco las palabras que creamos como última defensa ante la conciencia de nuestra propia muerte sirven, [ya] que no hablamos el lenguaje desde nuestra propia hubris de creador, sino que este [la Real Academia Española ya no acepta el acento sobre el pronombre demostrativo], en cierta manera nos habla. Por tanto, la obra autotélica, el mito de la última urna contra el caos y la sinrazón no es más que otra 
vasija ilusoriamente vacía. O llena" (cit. en Woolf 16). Tal y como señala Földényi, "el objetivo de la obra de crear un mundo lleva al fracaso, a la futilidad, a la nada que anida en la existencia. Toda obra de arte importante es utópica porque despliega la nada que acecha en el aquí y ahora; de ahí la tristeza y la desolación que menan de todas las obras modernas significativas" (154). El arte puede ser incluso "peligroso":
El arte es ambiguo: es democrático porque todos pueden entrar, y aristocrático porque pocos pueden convivir con esta posibilidad y porque menos aún son capaces de recorrer el camino hasta el final y descubrir allí, al descorrer [...] el velo que oculta la verdad de la poesía, la mirada amenazante de la nada. Estos pocos se abren a la melancolía [...]. El arte es "peligroso" [...] ya que una de sus principales tareas consiste en introducir en el mundo de los otros la soledad y el silencio definitivo (Földényi 156).

La nada asoma tras el todo pues, como dijimos, es "el punto de partida", sombra omnipresente del "algo", que delata el fracaso del lenguaje, si bien el autor osa "quebrantar el silencio con el ruido, sabiendo que toda escritura estriba en la nada y apunta a la nada". En palabras de Becket,
El arte es la apoteosis de la soledad. No hay comunicación posible porque no hay medio alguno para comunicarse. Incluso en las ocasiones en que sucede que la palabra o el gesto constituyen expresiones correspondientes a la personalidad, éstos pierden toda significación, como si tuviesen que atravesar el telón móvil de una catarata antes de alcanzar la personalidad opuesta. Bien hablamos y actuamos por nosotros mismos y, en tal caso, nuestro discurso y nuestros actos se ven deformados y vaciados de su sentido por una inteligencia distinta de la nuestra, o bien hablamos y actuamos en nombre de otro y, en este caso, nuestro discurso y nuestros actos no son más que mentiras (53).

Todos poseemos nuestro propio código comunicativo, cuyas entrañas ni siquiera nosotros mismos conocemos. "Estamos solos. No podemos conocer, como tampoco ser conocidos" (Becket 54), de modo tal que el (auto)conocimiento a través de los demás -anhelado en Invitación a la melancolía- parece también fracasado. He aquí la náusea de Sartre, la gratuidad de Camus, -el dolor, en definitiva- consustanciales al arte y a la literatura. El artista J. Eremy, uno de los personajes introducidos por Velasco en Invitación a la melancolía, expresa así el proceso creativo: 


\begin{abstract}
Cuando pinto, me siento muy solo y abandonado [...]. Sufro mucho, porque la creación es asumir la responsabilidad de un mundo más fuerte que nosotros, para el que no estamos preparados. Eso es lo peor, que nadie puede acompañarnos ni echarnos un cable cuando exploramos la cueva de nuestra imaginación, es aterrador. [...] Mi mente es perversa, la de un monstruo. [...] La soledad es un don y un castigo, lo mejor y lo peor que nos puede tocar (143).
\end{abstract}

Como ya dijo Capote en Música para camaleones, "cuando Dios le entrega a uno un don, también le da un látigo; y el látigo es únicamente para autoflagelarse". Se funde así la realidad vivida y la soñada en búsqueda de una nostalgie d'unité imposible, generando frustración. Así se nos hará saber en Invitación a la melancolía:
Mas quién era Velasco, el capitán, yo mismo; qué nos caracterizaba y definía sino esa vulnerabilidad, esa certeza de querer y no poder, melancolía o locura, Velasco, el capitán, mi pobre Nino, yo, querer y no poder. También Durero, el genio creador, soñaba más de lo que podía realizar. Es el tormento de saber y no lograr jamás la plenitud, de tener a mano el fruto y nunca alcanzarlo (129).

Para Andrés "las obras maestras hacen al hombre casi tan desdichado como el amor: [...] Prometen, pero al final no dan nada. Desearíamos fundirnos con ellas, incorporarlas a nosotros, pero nos rechazan y generan un anhelo que, carente de meta, no puede satisfacerse" (156). Esa misma experiencia la vive el creador, espoleado "a pintar, poner el sufrimiento, trabajar hasta el límite aunque no haya redención, aunque sepa que no vamos a sacar nada en limpio, que todo ha de ser un fracaso, también es posible gestionar el fracaso" (22). Y he aquí un aspecto esencial: la plenitud posible en el fracaso pues, como ya dijera Kavafis, lo que cuenta es el viaje y no llegar al destino. Y es la vida la aventura más maravillosa a la que nos enfrentamos. Su sinsentido y gratuidad nos hacen libres, nos permiten volar, uniendo así la realidad tangible a la fantaseada: "el hombre no ha nacido para aceptar el mundo, sino para crear el suyo propio, por lo que las cosas dadas y las creadas constituyen una unidad inseparable" (Martínez Oria 222).

Esta aceptación sincera del fracaso como punto de partida de un viaje sin destino fijo -más allá de la muerte-, tal vez sea la mayor aportación de la confluencia entre la fantasía y la literatura, más elevada respecto a la filosofía pues, en palabras de María Zambrano: 
Supone la novela una riqueza humana mucho mayor que la Filosofía, porque supone que algo está ahí, que algo persiste en el fracaso; el novelista no construye ni añade nada a sus personajes, no reforma la vida, mientras el filósofo la reforma, creando sobre la vida espontánea una vida según pensamientos, una vida creada, sistematizada. La novela acepta al hombre tal y como es en su fracaso, mientras la Filosofía avanza sola, sin supuestos (159).

Por lo tanto, la proyección de la fantasía (melancólica) en la literatura, aun siendo un fracaso -la ordenación ilusoria de una vida sin sentido, en constante movimiento-, va más allá al ser consciente del fracaso y hacernos partícipe de él. Nos permite adentrarnos, esta vez con gusto, en el sinsentido. La melancolía, esa mirada crítica, es el instrumento para explorar plenamente lúcidos el camino incierto de la vida. De hecho, "la tristeza es un estado cognitivo-afectivo tan necesario y beneficioso como la felicidad, si no más" (Martínez Oria 365-366). El arte y la literatura hacen suyo el fracaso del ser humano contingente, y se deleita en él:

por qué no pintar lo que hay en el instante fugaz, apresar el propio tiempo transcurriendo y desvelándose, capturar el aire intangible de los espacios que nos rodean y meterlo en el cuadro, hacer presente lo que se ve y también lo que no se ve, todo, incluido el yo que pinta y hasta el tú que observa (317).

Ahora bien, tal y como planteamos anteriormente, ¿es realmente la literatura una expresión sincera capaz de consolar al melancólico o, por el contrario, otro subterfugio teatral para ocultar realidad?

El arte es un falso consuelo para Roquentin en La nausée: “dire qu'il y a des imbéciles qui tirent des consolations dans les beaux-arts [...], ils se figurent que leurs souffrances deviennent musique, comme celles du jeune Werther; ils croient que la beauté leur est compatissante. Les cons" (244). Maupassant ni siquiera cree en el arte: "Pourquoi cette imitation vaine? Pourquoi cette reproduction banale de choses si tristes par ellemêmes? Misère!" (cit. en Minois 329). Sin embargo, para Schopenhauer, máximo exponente del pesimismo, la contemplación artística es la única vía de consuelo ante el sinsentido. Alicia Puleo señala a propósito de este filósofo que "solo ciertas actividades como el conocimiento puro o el arte nos transforman en espectadores desinteresados y nos alejan transitoriamente de este ciclo de sufrimientos" (Puleo 29-30). 
Esto nos permite "ne plus être acteur dans cette pièce tragique, mais spectateur d'un monde transfiguré" (Minois 315). Contemplamos así desde la seguridad del observador nuestra propia tragedia, pero tamizada y ordenada estéticamente. Ya Freud consideró ese "mundo transfigurado" como un espacio en el que el espectador se (re)encuentra en una experiencia catártica, especialmente cuando se abordan nuestros mayores miedos:

\begin{abstract}
Nuestros lazos sentimentales, la intolerable intensidad de nuestro duelo, nos inclinan a rehuir y evitar a los nuestros todo peligro. Excluimos así toda una serie de empresas peligrosas [...]. Entonces habrá de suceder que buscaremos en la ficción, en la literatura y el teatro una sustitución de tales renuncias. En estos campos aún encontramos hombres que saben morir e incluso matar a otros. Sólo en ellos se nos cumple también la condición bajo la cual podríamos reconciliarnos con la muerte (112).
\end{abstract}

Esto nos produce placer, pues según sostuvo en El creador literario y el fantaseo, "acaso contribuya en no menor medida a este resultado [el placer estético] que el poeta nos habilite a gozar en lo sucesivo, sin remordimiento ni vergüenza algunos, de nuestras propias fantasías" (135).

La Literatura nos enfrenta al sinsentido, a la muerte que nos recuerda nuestra naturaleza contingente. Así lo explica Ramón Andrés:
El público -tanto el lector como el espectador- se acostumbró a "ver morir" a sus héroes, convertidos una y otra vez en la encarnación de las proyecciones personales, las de cada uno, figuras que mostraban a todos la manera más desnuda de la fragilidad humana, aunque también su compromiso y capacidad de sacrificio. "Ver morir" en escena satisface una parte del deseo de muerte personal, toda vez que apacigua una voluntad de destrucción que tiene lugar en otro ser (293).

Así, la literatura se ofrece como medio para trascender, al considerar como Unamuno "más real a don Quijote que a Cervantes" (Martínez Oria 40). Don Quijote sigue vivo pero no así Cervantes. Y es que "la poesía es un hallazgo permanente de lo que existe en nosotros" (Martínez Oria 41). El narrador-autor de Invitación a la melancolía recoge una cita de Aristóteles, perteneciente a su Arte poética, que resume bien esta 
cuestión, puesto que "no es oficio del poeta el contar las cosas como sucedieron, sino como debieran o pudieran haber sucedido, probable o necesariamente" (45). Así, "la ficción aspira a pervivir en la realidad" (Martínez Oria 53) y, a su vez, el escritor persigue "el deseo de pervivir en la obra, imaginando lectores que podrían identificarse con sus sentimientos y advertir su alma aún viva y encendida" (Martínez Oria, Pervivir en la obra 54). Tal vez por ello, para Kristeva:

l'œuvre d'art qui assure une renaissance de son auteur et de son destinataire est celle qui réussit à intégrer dans la langue artificielle qu'elle propose (nouveau style, nouvelle composition, imagination surprenante) les émois innomés d'un moi omnipotent quelque peu endeuillé ou orphelin. Aussi une telle fiction est-elle sinon un antidépresseur, du moins une survie, une résurrection... (62)

La literatura es, por tanto, "non pas un antidépresseur neutralisant, mais un contre-dépresseur lucide" (Kristeva 35).

Invitación a la melancolía nos plantea, en definitiva, un tipo de melancólico en tanto que agente social capaz de devolvernos nuestra imagen oculta y proyectada tras el espejo de lo social. La negativa de muchos de sus personajes -incluido el narrador-protagonista autoficcional- a asumir los patrones socialmente establecidos, les lleva a (re)construir un universo propio, allí donde las palabras revelan la fragilidad y el sinsentido de la vida. El melancólico intenta darles contenido y forma mediante una actitud crítica hacia cuanto le rodea, también como categoría estética y creadora, en donde entran en juego la fantasía y la imaginación. Es capaz de unir armónicamente razón e imaginación atisbando con su intuición melancólica -inconformista, anhelante, siempre insatisfecha- algo que se le escapa, la nostalgie d'unité de Camus, un "appétit d'absolu", de eternidad, de unión del individuo contingente con el universo, la "mens" postulada por Ficino.

Pero la unión definitiva es imposible, pues "las obras maestras hacen al hombre casi tan desdichado como el amor: [...] Prometen, pero al final no dan nada. Desearíamos fundirnos con ellas, incorporarlas a nosotros, pero nos rechazan y generan un anhelo que, carente de meta, no puede satisfacerse". Al creador, a Andrés, solo le queda "pintar, poner el sufrimiento, trabajar hasta el límite aunque no haya redención, aunque sepa que no vamos a sacar nada en limpio, que todo ha de ser un fracaso, también es posible gestionar el fracaso". Y esta es, creemos, la 
mayor aportación de la literatura: la aceptación sincera del fracaso como punto de partida de un viaje sin destino fijo, "que algo está ahí, que algo persiste en el fracaso". Así, la proyección de la fantasía (melancólica) en la literatura, aun siendo un fracaso -la ordenación ilusoria de una vida sin sentido, en constante movimiento-, va más allá al ser consciente del fracaso y hacernos partícipe de él.

Atrás queda la parte más mezquina -nuestras pieles apolilladas, el deseo siempre insatisfecho- y sólo los jirones del alma se agitan, y se estiran y flotan hacia lo alto, sin consistencia, sin sentido.

\section{REFERENCIAS}

Andrés, Ramón. Semper dolens. Historia del suicidio en occidente. Barcelona: Acantilado, 2015. Impreso.

Aristóteles. El arte poética. Madrid: Espasa-Calpe, 1964. Impreso.

Aristóteles. El hombre de genio y la melancolía. Problema XXX, 1. Ed. Jackie Pigeaud. Barcelona: Quaderns Crema, 1996. Impreso.

Beckett, Samuel. Proust. 1931. Trad. Juan de Sola. Barcelona: Tusquets, 2013. Impreso.

Camus, Albert. Le mythe de Sisyphe. Essaie sur l'absurde. 1942. París: Gallimard, 2016. Impreso.

Földényi, Lászlo. Melancolía. 1984. Trad. Adan Kovacsics Barcelona: Galaxia Gutenberg, 2008. Impreso.

Freud, Sigmund. "Consideraciones de actualidad sobre la guerra y la muerte". El malestar en la cultura y otros ensayos. Trad. Luis López-Ballesteros de Torres. Madrid: Alianza, 1976. Impreso.

. Obras completas, vols. IX y XXI. Trad. José L. Etcheverry. Buenos Aires: Amorrortu, 1992. Impreso.

Jackson, Stanley W. Historia de la melancolía y la depresión desde los tiempos hipocráticos a la época moderna. Trad. Consuelo Vázquez de Parga. Madrid: Turner, 1986. Impreso.

Johnson, Samuel. History of Rasselas. Prince of Abyssinia. Ontario: In parentheses Publications. Orientalism Series, 1999. Impreso.

Kierkegaard, Sören. El concepto de la angustia. 1844. Madrid: Espasa Calpe, 1959. Impreso.

Klibansky, Raymond, Panofsky, Erwin y Saxl, Fritz. Saturno y la melancolía. Trad. María Luisa Balseiro. 1964. Madrid: Alianza, 2004. Impreso 
Kristeva, Julia. Soleil noir. Dépression et mélancolie. París: Gallimard, 1987. Impreso.

Martínez Oria, Andrés. "Novela, río total". Argutorio: revista de la Asociación Cultural "Monte Irago". 30, 2013: 43-47. Impreso.

. "Invitación a la melancolía". Argutorio: revista de la Asociación Cultural "Monte Irago". 31, 2014a: 59-63. Impreso. . Invitación a la melancolía. Astorga: CSED, 2014b. Impreso.

. "Pervivir en la obra: Ricardo Gullón y Enrique Gil y Carrasco". Argutorio: revista de la Asociación Cultural "Monte Irago". 39, 2018: 54-62. Impreso.

Minois, Georges. Histoire du mal de vivre. De la mélancolie à la depression. París: Éditions de la Martinière, 2003. Impreso.

Puleo, Alicia. Cómo leer a Schopenhauer. Madrid: Júcar, 1991. Impreso.

Rodríguez, Samuel. Universo femenino y mal. Estudio crítico de la narrativa de Espido Freire. Madrid: Universidad Autónoma de Madrid. Impreso.

Rotterdam, Erasmo de. Elogio de la locura. 1511. Trad. Teresa Suero Roca. Barcelona: Bruguera, 1974. Impreso.

Sartre, Jean-Paul. La nausée. 1938. París: Gallimard, 2003. Impreso.

Schopenhauer, Artur. El mundo como voluntad y representación. Trad. Pilar López de Santa María. Madrid: Trotta, 2004. Impreso.

Suárez Martínez, Luis Miguel. “Andrés Martínez Oria: Invitación a la melancolía". Web. 20 Abr. $2020<$ http//.astorgaredacción. com/not/ 3470/ la_metanovela_de_martinez_oria>.__. "Lecciones cervantinas: parodia, perspectivismo y metanovela en Invitación a la melancolía de Andrés Martínez Oria". Castilla. 5, 2014: 284-307.

Svendsen, Lars. Filosofía del tedio. 1999. Trad. Carmen Montes Cano. México, 2008.

Woolf, Virginia. La señora Dalloway. 1925. Ed. María Lozano. Trad. Mariano Baselga. Madrid: Cátedra, 2005. Impreso.

Zambrano, María. Los intelectuales en el drama de España y escritos de la guerra civil. 1939. Madrid: Trotta, 1998. Impreso.

\section{Como citar:}

Martínez Oria, Andrés. "Lenguaje, fantasía y literatura en Invitación a la melancolía". Discusiones Filosóficas. 36. 2020: 159-176. DOI: 10.17151/difil.2020.21.36.10. 